\section{«Die imaginäre Kraft des Wissens»}

\author{
E. Taverna
}

Stanislaw Lem, der grosse Altmeister der Sciencefiction, hat dieses Jahr seinen 80. Geburtstag gefeiert und auf sein Lebenswerk zurückgeblickt. Im damaligen sowjetischen Protektorat Polen lebend, vom Westen abgeschnitten und von der Zensur kontrolliert, hat Lem mit erstaunlicher Weitsicht technische und soziale Entwicklungen, wie die Biotechnik und Informatik, Jahrzehnte vor ihrem Durchbruch beschrieben. Lem studierte Medizin und war nach dem Staatsexamen als Assistent für Probleme der angewandten Psychologie tätig. Privat übersetzte er wissenschaftliche Publikationen besonders über Mathematik und Kybernetik und gründete eine astronautische Gesellschaft. Der spätere Dozent für Literatur in Krakau "erfand" bereits in den fünfziger und sechziger Jahren das Internet, die Intellektronik (künstliche Intelligenz) und die Phantomatik (virtuelle Realität). In seinen zahlreichen Schriften verbindet er Poesie und Spekulation in brillanten Sprachkunstwerken zu Erzählungen in einer Zukunft, die er in einfallsreichen Variationen roman- oder essayhaft thematisiert. Er sinniert über denkende Materie, über die Unsterblichkeit, über Waffensysteme des 21. Jahrhunderts, schreibt Robotermärchen und Sterntagebücher, erzählt von hirnlosen Klons, Vaganten des Kosmos und entwirft sein theoretisches Hauptwerk, das er in Anspielung auf die Scholastik "Summa technologiae" nennt. Lems zivilisationskritische Sicht hat im Alter an sarkastischer Schärfe zugenommen: "Unsere Lage, scheint mir, ähnelt dem genialen Gedanken eines Wilden, der das Funktionsprinzip der Steinschleuder erkannt hat und aufgrund dessen zu der Überzeugung gelangte, er könne bald auch ins Weltall fliegen.» Sein bisher letztes Buch "Riskante Konzepte» parodiert den Anspruch "die Natur ein- und überholen" mit der alten Losung "den Westen ein- und überholen». Sprachwitz und Ironie sind ihm etwas vergangen, zu real hat für ihn die Gegenwart seine Zukunftsvisionen eingeholt. Er mag nicht mehr mit seinem Welt- raumfahrer Ijon Tichy durch den Kosmos tingeln, lieber rechnet er mit den aktuellen Mythen und Allmachtsphantasien ab und dekonstruiert die gen- und nanotechnologischen Phantasien der Wissenschaftsjournalisten mit deren eigenen Argumenten. Der Futurologe Lem hat sich zum greisen Realisten gewandelt, der, wie schon sein Golem XIV dreissig Jahre zuvor, die populären "anti-ageing" Verheissungen als "vegetative Rettung" und "ein Leben, das nicht die Bohne wert ist", verhöhnt. Er misstraut sowohl dem Weltkapital wie dem E-government der direkten Demokratie, da für ihn die Menschen grundsätzlich an kurzsichtiger oder an weitsichtiger Dummheit leiden. Er mag sie nicht, diese Zukunft, die er vorausphantasiert hat. Seine rabenschwarzen Schlussworte sind vielleicht von seinem eigenen nahen Ende geprägt: "Selig tagträumend, werden die phantomatisierten Massen weiterhin Kinder gebären, doch wird diese Kinderschar als ausgeträumt und damit irreal selbst einen wichtigen Beitrag zum gefälligen Ende der Welt leisten, was, wie der unvergessene Kisielewski zu sagen pflegte, ich euch und mir wünsche.»

Weniger pessimistisch, aber nicht weniger klug und phantasievoll setzt sich das unimagazin, die Zeitschrift der Universität Zürich vom Oktober 2001, mit dem Thema «Science Fiction - Science Facts. Die imaginäre Kraft der Wissenschaft» auseinander. Intelligent, unterhaltend und phantasievoll berichten Forscher aus Publizistik, Geschichte, Informatik, Physik, Herzchirurgie und Immunologie, und Soziologen, Philosophen, Psychologen und Journalisten aus den brodelnden Ideenküchen der Labors, Seminare, Hörsäle und Operationsräume. Das Spektrum ist weit, reicht von künstlichen Frauen über kosmische Familienromane $\mathrm{zu}$ verrückten Wissenschaftlern, von DNS-Drähten über Herzroboter zu Schaubühnen ferner Welten. Auch die Geschichte des Literaturgenres wird selbst für Nichtliebhaber kenntnisreich und unterhaltend rezeptiert. Das Magazin, eine überaus lesenswerte Lektüre, wird von der Universitätsleitung herausgegeben und erscheint viermal jährlich. Natürlich ist das Magazin auch im Internet abrufbar: www.unicom.unizh.ch/magazin.

\footnotetext{
- Stanislaw Lem: Riskante Konzepte. Frankfurt am Main, Leipzig: Insel Verlag; 2001.

- Unimagazin 3/01, unicommunication, Schönberggasse 15a, 8001 Zürich, Tel. 016344430.
} 